\title{
O ÍNDIO BRASILEIRO NO LIVRO DIDÁTICO
}

Leandro Henrique Magalhães ${ }^{1}$

Resumo: O presente artigo tem por objetivo entender como o índio brasileiro vem sendo tratado nos livros didáticos. Para tanto, o trabalho está dividido em três partes: na primeira, apresentaremos o modo como o índio foi visto pelos primeiros portugueses, na segunda como este nativo vem sendo pensado nas pesquisas mais recentes sobre o tema e por fim, o modo como o livro didático apresenta a questão. Com isso, pretenderemos apontar caminhos que possibilite uma maior compreensão acerca da diferença.

Unitermos: Livro Didático, Índio, Alteridade

\section{Introdução}

O presente artigo tem por objetivo analisar como o índio brasileiro é apresentado nos livros didáticos de $1^{\circ}$. e $2^{\circ}$. graus e assim, apontar caminhos que possibilite a compreensão do modo como vem sendo entendido pelo outro. Pretende-se assim colaborar para amenizar a visão que se tem acerca do indígena que, segundo Luiz Donisete Benzi Grupioni, é:

"A imagem de um índio genérico, estereotipado, que vive nu no mato, mora em ocas e tabas, cultua Tupã e Jaci e que fala Tupi e permanece predominantemente, tanto na escola como nos meios de comunicação (GRUPIONI, 1995, p.483)."

\footnotetext{
${ }^{1}$ Doutorando em História na Universidade Federal do Paraná - UFPR. Professor de Introdução às Ciências Sociais na Faculdade do Norte Pioneiro - FANORPI.
} 
Destacaremos aqui o período colonial brasileiro, mais especificamente da chegada dos primeiros colonos até o início do século XVIII. Pretende-se assim pensar o nativo quando se tem as primeiras impressões sobre ele, sendo este recorte privilegiado por ser o momento em que o índio mais aparece no livro didático. Para uma melhor compreensão do tema tratado, dividiremos o artigo em três partes: na primeira, apresentaremos o modo como o índio foi visto pelos primeiros portugueses, na segunda como este nativo vem sendo pensado nas pesquisas mais recentes sobre o tema, e por fim, o modo como o livro didático apresenta a questão.

\section{Primeiros contatos: em direção a um novo mundo}

A descoberta da América possibilitou um encontro entre dois mundos totalmente diferentes, com simbologias e valores distintos e muitas vezes excludentes (TODOROV, 1996). Tal encontro provoca um confronto entre sistemas de valores e crenças, agravado com a presença de negros africanos e cristãos novos ${ }^{2}$. Para melhor compreendermos como os europeus entendiam a questão da diversidade, faz-se necessária uma análise, mesmo que sucinta, de seu imaginário no período.

A Europa dos séculos XV e XVI possuía um imaginário simbólico repleto de crenças ligadas ao maravilhoso. Seu mundo era então restrito a uma pequena porção do globo, já que grande parte deste era desconhecido, o que permitia uma série de especulações (O'GORMAN, 1992). A chegada dos europeus em território americano aguça este imaginário, transpondo para a colônia uma infinidade de representações do real. Segundo Giulia Lanciani (1990/1991), a necessidade de traduzir algo estranho (ou não identificável) para um sistema simbólico

2 Cristão novo era a denominação dada aos judeus recém convertidos, principalmente a partir da obrigatoriedade da conversão, ordenada pelo rei $D$. Manuel (NOVINSKY, 1992; SARAIVA, 1985; SIQUEIRA, 1978). 
conhecido, acaba por tornar-se um campo fértil para o florescimento deste maravilhoso. Porém, à medida em que alguns símbolos, antes desconhecidos, são decifrados, o maravilhoso começa a desfazer-se, e a realidade adquire novo significado no espaço colonial.

Laura de Mello e Souza, em livro intitulado "O diabo e a terra de Santa Cruz" (1986), apresenta algumas considerações acerca do imaginário do europeu acerca do espaço colonial que são aqui pertinentes. A autora demonstra que o indígena era entendido pelo colono como uma espécie de besta ou monstro, além de ser caracterizado como selvagem e inferior. Sua religiosidade era tida como irracional, adquirindo, porém, características humanas quando se admitia a possibilidade de cristianização. O índio seria situado dentro de uma humanidade de caráter universal, que justificaria a conversão, ignorando-se as especificidades culturais e criando-se uma identidade a partir desta igualdade, definida pelos preceitos cristãos, e não indígenas, tendo em vista que estes buscavam a manutenção de uma identidade baseada na diferença (MAGALHÃES, 1999). Havia assim a necessidade de inserir o nativo na história européia, onde muitos jesuítas os identificaram como descendentes de Caim, o maldito, filho perdido de Noé, além de encontrar pistas da vinda de São Tomé, apóstolo e pregador, para as terras do Brasil.

"Quando os portugueses descobriram o Brasil, acharam as pegadas de São Tomé estampadas em uma pedra que hoje se vê nas praias da Baía; mas rasto, nem memória da fé que pregou São Tomé, nenhum acharam nos homens. (VIEIRA, 1951, p.405)"

A distinção existente entre o universo cultural dos jesuítas e dos nativos obriga os primeiros a formularem meios de converter signos e costumes cristãos para a linguagem indígena, o que acaba criando uma espiritualidade própria pois, apesar 
da tentativa de trabalhar com o sistema simbólico dos nativos, este acaba por tomar características distintas do cristianismo (BOSI, 1992). Um aspecto importante que deve ser aqui realçado é a influência que a Contra Reforma teria neste momento, principalmente entre os jesuítas, tendo em vista que o Concílio de Trento, ao debater as teses defendidas por Lutero, afirmaria a universalização da Igreja aliada a necessidade de expansão da fé, tendo no catolicismo a religião hegemônica e universal, sendo missão da igreja levar o evangelho a toda criatura (GREEN, 1984).

O Concílio de Trento justifica a expansão do cristianismo partindo da noção de Lei Natural ${ }^{3}$, segundo o qual todo homem teria capacidade de saber o que era certo ou errado. Esta noção afetaria diretamente as ações missionárias na América, que seria entendida de modo distinto entre padres católicos e protestantes. Segundo Alcir Pécora (1992), a visão dos protestantes frente ao novo mundo e seus habitantes era a de nostalgia de um tempo perdido onde o homem, devido à sua inocência, não necessitaria ainda da intervenção do Estado em sua vida ${ }^{4}$. Viam o índio como o bom selvagem, porém, impossibilitado de converter-se pois, segundo o dogma da predestinação, "o

\footnotetext{
${ }^{3}$ Segundo os teóricos do Concílio de Trento, o homem, logo após ser expulso do paraíso, passou a viver em estado de natureza, segundo sua consciência, sem um poder superior para guiá-lo. Esta ausência era no entanto, ilusória, haja visto que, pelo fato de Deus tê-lo dotado de razão, ele seria capaz de identificar por si suas doutrinas. Neste estado natural, não havia a necessidade de persuasão entre os homens, pois cada indivíduo agia por sua consciência. No entanto, por ser ele um ser caído, havia uma tendência para o egoísmo e para a negação do outro, o que o levou a se organizar para formar um Estado de direito que o auxiliasse a seguir corretamente o estado de natureza. Assim, há uma delegação de poderes para uma pessoa que iria governar em nome das outras com o objetivo de garantir o bem comum (SKINNER, 1996).

${ }^{4}$ Este tempo perdido configura-se de modo diferenciado do estado de natureza defendido pelos católicos, pois os protestantes não acreditavam que houvesse uma lei natural que guiasse o homem dotado de razão, mas sim uma ingenuidade que se perde com a expulsão do paraíso, sendo que, devido a esta expulsão, fizera-se necessário a instituição de governos de caráter divino.
} 
selvagem americano quedaria definitivamente excluído da salvação (PÉCORA, 1992, p.35)". Sua imagem estaria vinculada a idéia de uma época paradisíaca perdida, associado a um pessimismo escatológico.

Entre os jesuítas, porém, predominava uma visão diferenciada pois, ao aceitar que os índios eram dotados de razão, esperava-se sua conversão, o que possibilitaria sua inserção no catolicismo. Não se tinha, ao contrário dos protestantes, uma visão do bom selvagem, mas sim a do índio bárbaro, boçal e preguiçoso. Esta imagem aparentemente negativa era associado aos seus maus costumes, o que poderia ser estirpado com a atuação da Igreja.

Esta visão não era, no entanto, única entre os católicos. Muitos portugueses recém chegados à América defendiam a escravidão indígena como único meio de sustentarem-se, principalmente em regiões onde o tráfico de escravos era dificultado, como em São Paulo e no Nordeste Brasileiro. Esta diferença de entendimento seria o motor de diversos conflitos entre colonos e jesuítas, que tinham interesses distintos em relação ao nativo. Como casos marcantes, podemos citar a expulsão dos jesuítas do Maranhão em 1661 e o ataque de bandeirantes paulistas à missões do sul da América.

Havia assim diversos interesses em relação aos indígenas, vinculados com os diferentes projetos que se desejava implantar, o que moldaria as visões acerca dos nativos. Assim, ao denominar os nativos de bárbaros e incapazes, reforçava-se a necessidade da escravidão, enquanto que ao representá-los como cristãos em potencial, justifica-se a atuação missionária na América Portuguesa.

\section{Segundo contatos: o nativo na historiografia}

Apresentaremos aqui, de modo sucinto, algumas obras recentes que tratam especificamente da questão indígena, seja pela ótica do europeu, seja pela do nativo. Uma contribuição 
importante foi dada por Tzvetan Todorov em seu livro intitulado "A conquista da América: a Questão do Outro" (1996). O autor busca aqui compreender os nativos como diferentes em relação a um outro, o europeu, não os classificando como superiores ou inferiores. No entanto, o indígena, não ganha vida em seu trabalho, visto que o autor dedica-se a interpretar a visão que os europeus possuíam dos astecas.

Tzvetan Todorov procura compreender este universo empreendendo uma releitura da prosa colonial ${ }^{5}$ a partir da crítica histórico-literária. Segundo ele, não se pode ler esses textos como enunciados transparentes, mas sim levar em consideração o ato e as circunstâncias de sua enunciação, em outras palavras, considerar as dimensões sócio-espaço-temporais presentes na construção da trama narrativa.

Outro autor que trata da questão indígena de forma inovadora é o historiador Ronaldo Vainfas que em seu livro intitulado "A Heresia dos Índios" (1995) consegue, de forma surpreendente, trabalhar tanto com o modo como os nativos eram entendidos pela Inquisição, como também identificar algumas características do convívio entre estes e os europeus. Apresenta, além disso, a visão do indígena acerca da catequização, possibilitando que entendamos algumas manifestações nativas como uma tentativa de reação a dominação sócio cultural imposta pelos europeus.

O autor nos dá um exemplo de assimilação do cristianismo pelos índios brasileiros, apresentando como um grupo de indígenas das proximidades da Bahia insere características cristãs em um mito nativo, que passa a ser conhecido como Santidade de Jaquaripe pelos contemporâneos. O cristianismo pregado pelos padres jesuítas acabava assim por adquirir sentidos diversos, que resultaria em uma religiosidade nem nativa, nem cristã, reafirmando a tese defendida por Alfredo Bosi (1992).

\footnotetext{
${ }^{5}$ Tomo de empréstimo a expressão de Alfredo Bosi, na Dialética da Colonização, para definir os escritos que são conhecidos como crônica colonial (BOSI, 1992).
} 
Seguindo o mesmo caminho, Eduardo Viveiro de Castro (1992) apresenta-nos as dificuldades que os missionários, em especial os padres da Companhia de Jesus, teriam para entender o nativo. Parte, para tanto, do discurso da inconstância da alma selvagem, que seria para os jesuítas o principal motivo de evasão nas missões. O autor apresenta-nos tanto o modo como os jesuítas entendiam o nativo como o contrário pois, segundo ele, os padres da Companhia de Jesus não compreendiam a cultura Tupinambá, que era marcada pelo convívio com a diferença e pelo transite entre diversas culturas. $O$ discurso da inconstância seria assim resultado do não entendimento dos indígenas por parte dos missionários, pois os nativos teriam uma perspectiva de interação com o outro, enquanto que o europeu privilegiaria uma perspectiva assimilacionista.

Cito também aqui o livro de Ronald Raminelli, "Imagens da Colonização" (1996) que, partindo das representações do índio americano idealizadas por europeus, busca compreender sua polissemia, sempre identificadas com um determinado projeto colonial. Ou seja, procura verificar como o índio fora inserido no imaginário europeu nos séculos XV ao XVII. Segundo o autor, sem entender tais representações torna-se impraticável a compreensão das relações que se davam no período, além de impossibilitar um entendimento mais preciso das políticas indigenistas, tanto do período como as discutidas e implantadas posteriormente.

Ainda segundo o autor haveria, no período, dois meios primordiais de representação do índio americano: as narrativas oriundas de uma observação direta dos colonizadores, e a pintura. No caso das representações pictóricas do nativo brasileiro, eram realizadas, na maioria das vezes por artistas que não conheciam a América, estando distantes da realidade que procuravam representar. Acabavam, assim, apresentandoo a partir de sua expectativa e de seus padrões estéticos, inserindo traços e características que não faziam parte de tais culturas nativas ${ }^{6}$. Segundo Laura de Mello e Souza:

\footnotetext{
${ }^{6}$ Esta era uma prática corrente no período. A própria inquisição, ao deparar-se com outras culturas que não as ocidentais, encontram características cristãocidentais naquilo que não era entendido, possibilitando a identificação de
} 
"Não se apresentava o que se tinha diante dos olhos, mas o que era possível e lícito representar, segundo normas e cânones bem definidos (apud RAMINELLI, 1996, p. 09)."

O índio representado era aquele que interessava ao domínio europeu, ou seja, bárbaro, selvagem, antropófago , incapaz de gerir a vida, legitimando a dominação, tanto econômica como política e espiritual, dependendo da expectativa em relação a ele. Assim, segundo a leitura de Ronald Raminelli (1996), é necessário vincular as representações acerca do nativo com os diversos projetos coloniais existentes no momento.

\section{O índio brasileiro no livro didático}

O livro didático é hoje o principal instrumento utilizado em sala de aula, tanto pelos professores como por alunos. É nele que o conteúdo escolar encontra-se sistematizado e os conhecimentos e técnicas fundamentais para dada sociedade é transmitida para as novas gerações (BITTENCOURT, 1997, P.72). Deve assim ser entendido como portador de um sistema de valores, de ideologias e culturas, reproduzindo os interesse e o saber oficial impostas por setores da sociedade (BITTENCOURT, 1997, P.72; CARVALHO, 1997, P. 328), podendo ser considerado como instrumento de legitimação e poder, além de representativo de universos culturais específicos (LIMA E FONSECA, 1999, $\mathrm{P}, 203-212)$. Nas palavras de Thais Nívea de Lima e Fonseca:

bruxaria e satanismo em povos que não entendiam tais expressões. Temos aí um reflexo da opinião do grupo que está no poder, trazendo em si as marcas dos conceitos que queria encontrar. Como diria Michelet: "Somente a Europa teve a idéia nítida do Diabo, o procurou e o desejou. Só ela adorou o mal absoluto, ou pelo menos o que se supunha ser tal (MICHELET, 1992, p.10)". (GINSBURG, 1990/1991). 
"Ao lado de outras fontes - jornais e revistas, iconografia, discursos e obras teóricas - os manuais didáticos apresentam-se como parte essencial de uma determinada formação política e de um determinado contexto cultural (LIMA E FONSECA, 1999, P.204)."

Atualmente, os conflitos étnicos e religiosos aliados a um mundo cada vez mais globalizado, leva-nos a uma preocupação com a alteridade, fazendo-se necessário refletir acerca da diferença. O livro didático constitui-se, para grande parte das pessoas, como fonte única de informações sobre outras culturas e povos, contribuindo significativamente para a formação de uma imagem sobre o outro (GRUPIONI, 1995, P.486).

Segundo Luis Donisete Benzi Grupioni (1995), em quase todos os livros didáticos haveria afirmações contra o racismo e o preconceito, encorajando o respeito e a tolerância com o diferente. Porém, devido às dificuldades de se lidar com as diferenças étnicas e sociais, a alteridade é colocada no passado, distanciando-se de nossa realidade. $O$ índio é visto assim como algo estranho, que teria vivido em uma época e lugar distante do nosso, o que contribuiria para uma visão preconceituosa, entendida como um conceito ou juízo formado antes de se reunir informações suficientes sobre determinado assunto ${ }^{7}$.

Procuraremos aqui compreender o modo como o nativo aparece no livro didático. Para tanto, analisaremos dez deles, de $1^{\circ}$ e $2^{\circ}$. graus. Para identificarmos se houve ou não alterações no modo de se entender a questão indígena, optamos por utilizar, também, livros que não estão em catálogo, sendo dois do ano de 1991, um de 1992 e um de $1993^{\circ}$.

\footnotetext{
${ }^{7}$ Nas palavras do autor: "Trata-se de um conceito antecipado, de uma opinião que se forma sem conhecimento total dos fatos e sem a preocupação de uma reflexão mais apurada sobre o assunto (GRUPIONI, 1995, p.483)".

${ }^{8}$ LUCCA, 1991, $1^{\circ}$. grau; SANTOS, 1992, 2०. grau; PILETTI, 1996, $1^{\circ}$. grau; COTRIM, 1993, $2^{\circ}$. grau; MACEDO, 1996, $1^{\circ}$. grau; RIBEIRO, 1996, $2^{\circ}$. grau; BOULOS JR, 1998, $1^{\circ}$. grau; PILETTI, 1998, $2^{\circ}$. grau; MOTA, 1996, $1^{\circ}$. grau; CAMPOS, $1991,2^{\circ}$. grau.
} 
Se fizermos uma análise das capas destes livros, teremos que seis delas, ou seja, $60 \%$, possuem figuras de índios. Em duas, os índios são apresentados observando os europeus: no quadro de Victor Meirelles, intitulado "Primeira Missa do Brasil", de $1861^{9}$, e em uma figura de caravelas chegando ao continente recém descoberto ${ }^{10}$. Em outras três, o índio é colocado lado a lado com negros e brancos, dando idéia de interação e miscigenação ${ }^{11}$. Em duas há fotos de índios contemporâneos ${ }^{12}$. Tais capas dão a idéia de passividade, pois acabam por minimizarem os conflitos. Ou seja, apesar de $60 \%$ dos livros apresentarem índios em suas capas, estes estão, com exceção de um deles ${ }^{13}$, ou em relação ao europeu, ou lado a lado com ele.

A respeito da postura de cada autor, podemos identificar uma sensível mudança de perspectiva dos livros em catálogo em relação aos mais antigos. Nos mais recentes, há uma preocupação em demonstrar que a América era habitada antes da chegada dos europeus, traçando-se um pequeno histórico da chegada destes habitantes na América, além de apresentar quais seriam os meios necessários para estudá-los ${ }^{14}$. Estes autores chamam a atenção para a violência da conquista, onde é possível encontrarmos afirmações do tipo: "toda riqueza da terra pertencia aos índios (p.54) ${ }^{15 "}$ e, em pelo menos um dos casos, questiona-se explicitamente o uso do termo descoberta ${ }^{16}$, tendo em vista que este só faria sentido a partir de uma perspectiva européia, ignorando-se a dinâmica própria das populações americanas (GRUPIONI, 1995, P. 488).

\footnotetext{
${ }^{9}$ Sobre o quadro de Victor Meirelles, ver: COLI, 1998.

10 LUCCA, 1991; RIBEIRO, 1996.

11 SANTOS, 1992; MACEDO, 1996; MOTA, 1996.

12 MACEDO, 1996; PILETTI, 1998.

13 PILETTI, 1998.

${ }^{14}$ MACEDO, 1996; MOTA, 1996; RIBEIRO, 1996; BOULOS JR, 1998; PILETTI, 1998; PILETTI, 1996.

15 MACEDO, 1996.

${ }^{16}$ BOULOS JR, 1998.
} 
Apesar do bom começo, estes livros dedicam no máximo dois capítulos a esta questão, geralmente denominados de "A Origem do Homem Americano" e "O Brasil dos Índios", retomando-se a partir daí a saga dos portugueses em território americano. Tal afirmação pode ser constatada ao verificarmos quais os momentos em que o índio aparece nas narrativas dos livros didáticos, sendo eles: origem do homem americano, chegada dos europeus, extração do Pau Brasil, aprisionamento dos índios por bandeirantes e a evangelização jesuítica nas missões. Ou seja, apesar das propostas de diferentes abordagens, os índios são analisados em momentos idênticos, privilegiando-se os marcos europeus em detrimento de possíveis marcos indígenas.

Ainda assim o modo de abordagem diferencia-se de um autor para outro. Uma primeira constatação é que nos livros de $2^{\circ}$. grau os índios praticamente desaparecem, sendo tratados em breves passagens e sempre em relação ao europeu. Seria então no $1^{\circ}$. grau que a questão seria mais debatida. Os nativos seriam mais lembrados nos livros que tendem ao marxismo, onde podemos encontrar discussões acerca de sua exploração e não passividade frente às agressividades dos colonos ${ }^{17}$. Tende-se também a tratar da diversidade cultural, porém com menos sucesso, pois o outro permanece desaparecido em grande parte do trabalho, ressurgindo apenas em momentos específicos.

A questão da alteridade é também tratada por autores que buscam enfatizar a questão cultural da conquista, procurando destacar as diferenças entre índios e brancos. Em alguns casos podemos encontrar debates acerca da resistência indígena e sobre a aculturação ${ }^{18}$. Tais questões aparecem geralmente no momento em que é discutida a evangelização indígena pelos jesuítas que são, em alguns casos, acusados

${ }_{17}$ PILETTI, 1998; PILETTI, 1996; SANTOS, 1992; CAMPOS, 1991; COTRIM, 1993. 18 MACEDO, 1996; RIBEIRO, 1996. 
de imposição cultural ${ }^{19}$. Porém, na maioria das vezes, os conflitos são ignorados, destacando-se a perspectiva dos jesuítas em relação às missões. É possível encontrar nestes livros capítulos intitulados "A Religião Católica no Brasil Colônia" e "Cultura no Brasil Colonial"20 ou "O Encontro das Diferenças"21. No entanto, apesar dos títulos, apresentam as diferenças culturais de modo estanque, sem contatos ou conflitos, e quando estes aparecem, se dão em momentos específicos, sendo que nos demais permanece a visão européia sobre a colonização.

A partir das análises destes livros, podemos verificar que, como afirma Ernesta Zamboni, a mudança temática nos livros didáticas são geralmente superficiais, onde o conhecimento histórico mantem-se como verdade absoluta, sendo homogeneizante e sem problematização, estando ainda mais próxima da história social e econômica que da cultural (ZAMBONI, 1998). Concordamos também com Luiz Donisete Benzi Grupioni (GRUPIONI, 1995), quando afirma que o livro didático teria o poder de fazer aparecer e desaparecer o índio na História do Brasil. Não há assim um preparo para o entendimento e a convivência com a diferença, pois além do índio ser colocado no passado, é pouco explorado, o que contribuiria, como visto acima, para o preconceito e a discriminação.

Se compararmos o modo como os livros didáticos tratam a questão indígena com as interpretações dadas pelos colonos e pela historiografia recente, poderemos concluir que os livros didáticos mantém-se distante de ambas perspectivas. No primeiro caso, a questão da diversidade era central, gerando debates e conflitos, geralmente vinculados aos diversos interesses coloniais. Tal importância é ignorada pelos livros didáticos, que acabam por deixar o nativo em segundo plano nas relações coloniais.

\footnotetext{
19 PILETTI, 1996; MACEDO, 1996.

20 PILETTI, 1996.

21 RIBEIRO, 1996.
} 
No caso da historiografia há uma preocupação tanto com a visão do nativo como com a do colono acerca da colonização, onde é identificado um convívio não pacifico, mas intenso entre eles. Destaca-se assim as diferenças culturais e o entendimento que ambos tinham do outro, questão apontada por alguns livros didáticos, mas que não é desenvolvida. Além disso, privilegiase a visão européia acerca da conquista, tendo em vista que até mesmo as imagens utilizadas nestes livros teriam sido produzidas por europeus ${ }^{22}$. Confirma-se assim os prognósticos dados por Holien Gonçalves Bezerra (BEZERRA, 1999, P. 195202) e Décio Gatti Júnior (GATTI JR., 1999, P. 213-223), ao afirmarem que o livro didático estaria sendo incapaz de incorporar as inovações apontadas pela historiografia, mesmo quando há uma opção clara por determinada linha historiográfica, como é o caso do marxismo e da história nova.

Por fim, podemos afirmar que os conflitos presentes nos referidos livros seriam mais entre europeus, que disputavam a posse do novo mundo, que entre índios, ou africanos, e europeus. Acabam assim por identificar nos portugueses os fundadores da nação brasileira, que teriam por obrigação defender o território contra os ataques estrangeiros. Ou seja, apesar de iniciarem inovando, identificando nos nativos os donos da terra, acabam por confirmar a supremacia dos portugueses.

\footnotetext{
22 Entre as imagens que mais aparecem, podemos citar: "Chegada de Tomé de Souza à Bahia", "Partida de Estácio de Sá", de Benedito Calixto, "Terras Brasilis", de Lopo Homem Reinéis, "Viagem à Terra do Brasil", de Jean de Léry e, a campeã de todas, "Primeira Missa do Brasil", de Victor Meirelles. Segundo Circe Bittencourt, tais imagens estariam presentes nos livros didáticos desde os fins do século XIX, privilegiando-se uma visão européia da colonização. Ainda segundo a autora, imagens do povo brasileiro começaram a ser introduzidas recentemente nestas publicações, o que pode ser comprovado nos livros aqui analisados (BITTENCOURT, 1997, p. 77-82).
} 


\section{Bibliografia}

BEZERRA, Holien Gonçalves. O Processo de Avaliação de Livros Didáticos. In: NODARI, Eunice; PEDRO, Joana Maria; IOKOI, Zilda M. Gricoli. História - Fronteiras: Anais do XX Simpósio Nacional de História. São Paulo: Humanitas/ ANPUH, 1999, p. 195 - 202;

BITTENCOURT, Circe. Livros didáticos entre textos e imagens. In: BITTENCOURT, Circe (Org.). O Saber Histórico na Sala de Aula. São Paulo: Contexto, 1997.

BOSI, Alfredo. Dialética da Colonização. São Paulo: Companhia das Letras, 1992.

CARVALHO, Silvana Maria Batista de. O Livro Didático e as Concepções Historiográficas: Uma Análise do Ensino de História no $1^{\circ}$. e $2^{\circ}$. Graus. História e Cultura: $V$ Encontro Regional de História. Ponta Grossa: UEPG, 1997, p. 325-331. COLI, Jorge. Primeira missa e invenção da América. In: NOVAES, Adauto (Org.). A descoberta do homem e do mundo: Brasil 500 anos - experiência e destino. São Paulo: Companhia das Letras/ FUNARTE, 1998.

GATTI JR, Décio. Um Itinerário de Desigualdades: Livros Didáticos de História e Massificação do Ensino na Escola Brasileira (1960-1990). In: NODARI, Eunice; PEDRO, Joana Maria; IOKOI, Zilda M. Gricoli. História - Fronteiras: Anais do XX Simpósio Nacional de História. São Paulo: Humanitas/ ANPUH, 1999, p. 213-223.

GREEN, V.H.H. Renascimento e Reforma Luterana. Lisboa: Dom Quixote, 1984.

GRUPIONI, Luís Donisete Benzi. Livros didáticos e fontes de informações sobre as sociedades indígenas no Brasil. In: LOPES DA SILVA, Aracy \& GRUPIONI, Luís Donisete Benzi. A temática indígena na escola: novos subsídios para professores de $1^{\circ}$ e $2^{\circ}$ graus. Brasília: MEC/MARI/ UNESO, 1995.

GINSBURG, Carlo. O Inquisidor como antropólogo. Revista Brasileira de História: América Américas. São Paulo: ANPUH/Marco Zero, v. 11 no 21, set/90 - fev/91. 
LANCIANI, Giulia. O Maravilhoso como critério de diferenciação entre sistemas culturais. Revista Brasileira de História. São Paulo: Marco Zero, set.90/fev.91, v. 11 no21.

LIMA E FONSECA, Thais Nívea de. O Livro Didático de História: Lugar de Memória e Formador de Identidades. In: NODARI, Eunice; PEDRO, Joana Maria; IOKOI, Zilda M. Gricoli. História - Fronteiras: Anais do XX Simpósio Nacional de História. São Paulo: Humanitas/ ANPUH, 1999, p. 203-212. MAGALHÃES, Leandro Henrique. Olhares sobre a colônia: Vieira e os índios. Londrina: UEL, 1999.

MELLO E SOUZA, Laura de. O diabo e a terra de Santa Cruz: feitiçaria e religiosidade popular no Brasil Colonial. São Paulo: Cia das Letras, 1986.

MICHELET, Jules. A feiticeira. Rio de Janeiro: Nova Fronteira, 1992 NOVINSKY, Anita. Cristãos Novos na Bahia: A Inquisição. São Paulo, Perspectiva, 1992.

O'GORMAN, Edmundo. A invenção da América. São Paulo: EDUNESP. 1992.

PÉCORA, Alcir. O bom e o boçal ou o selvagem americano entre calvinistas franceses e católicos ibéricos. Remate de Males. Campinas, UNICAMP, 1992, n 12, p. 35 - 44.

RAMINELLI, Ronald. Imagens da colonização. São Paulo / Rio de Janeiro: EDUSP/FAPESP/ZAHAR, 1996.

SARAIVA, Antonio José. Inquisição e cristãos-novos. Lisboa: Estampa, 1985.

SIQUEIRA, Sonia A . A Inquisição portuguesa e a sociedade colonial. São Paulo: Ática, 1978.

SKINNER, Quentin. As fundações do pensamento político moderno. São Paulo: Companhia das Letras, 1996.

TODOROV, Tzvetan. A conquista da América: a questão do outro. $2^{\mathrm{a}}$. ed. São Paulo: Martins Fontes, 1996.

VAINFAS, Ronaldo. A heresia dos índios. Catolicismo e rebeldia no Brasil Colonial. São Paulo: Companhia das letras, 1995. VIEIRA, Padre Antonio. Sermão do Espírito Santo. In: Sermões. Lisboa: Lello \& Irmão, 1951. 
VIVEIRO DE CASTRO, Eduardo. O mármore e a murta: sobre a inconstância da alma selvagem. Revista de Antropologia. São Paulo: USP, 1992, v.35, p. 21-74.

ZAMBONI, Ernesta. Representações e Linguagens no Ensino de História.. Revista Brasileira de História. São Paulo: ANPUH/Humanitas, v. 18 no 36, 1998, p. 89-102.

\section{Fontes}

BOULOS JR, Alfredo. História do Brasil Colônia. São Paulo: FTD, 1998.

CAMPOS, Raymundo. História do Brasil. São Paulo: Atual, 1991 (2०. grau).

COTRIM, Gilberto. História do Brasil: para uma geração consciente. São Paulo: Saraiva, 1993.

LUCCA, Elian Alabi. Brasil: As origens, a colonização e a independência. São Paulo: Saraiva, 1991.

MACEDO, José Rivail; OLIVEIRA, Mariley W. Brasil: Uma História em Construção. São Paulo: Editora do Brasil, 1996. MOTA, Carlos Guilherme; LOPEZ, Adriana. História e Civilização: O Brasil Colonial. São Paulo: Ática, 1996.

PILETTI, Nelson. História do Brasil. São Paulo: Ática, 1998.

PILETTI, Nelson; PILETTI, Claudino. História e Vida. Brasil: Da Pré-História a Independência. São Paulo: Ática, 1996.

RIBEIRO, Vanise; ANASTÁSIA, Carla. Brasil: Encontros com a História. São Paulo: Editora do Brasil, 1996. SANTOS, Joel Rufino dos. História do Brasil. São Paulo: FTD, 1992. 
Abstract: The present article has the purpose to understand how the Brazilian indian is being treated in the text books. For so much, the work is divided in three parts: in the first, we will present the way how the indian was seen by the first Portuguese men, in the second how this native is being thought in the most recent researches on the theme and finally, the way the text book presents the subject. In this way, we will intend to point ways that make a larger understanding concerning the difference.

Key Words: Text Book, Indian, Alterity. 